\title{
Predictivity of CNC machine-induced vibrations on inter-story floors based on coupled experimental- numerical investigations
}

\author{
Enrico Bergamo, Marco Fasan and Chiara Bedon*

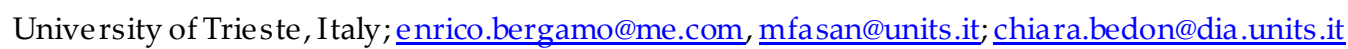 \\ * Corre spondence: chiara.bedon@dia.units.it; Tel.: +39-040-558-3837
}

\begin{abstract}
Machine-induced vibrations and their control represent, for several reasons, a crucial design issue for buildings, and especially for industrial facilities. A special attention is required, at the early design stage, for the structural and dynamic performance assessment of the load-bearing members, given that they should be optimally withstand potentially severe machinery operations. To this aim, how ever, the know ledge of the input vibration source is crucial. This paper investigates a case-study eyew ear factory built in Italy during 2019 and characterized by various non-isolated $\mathrm{CNC}$ vertical machinery centers mounted on the inter-story floor. Accordingly, the structure started to suffer for pronounced resonance issues. Following the past experience, this paper reports on the efficiency of a coupled experimental-numerical method for generalized predictive and characterization studies. The advantage is that the machinery features are derived from on-site experiments on the equipment, as w ell as on the floor. The experimental outcomes are then assessed and integrated with the support of FE numerical simulations, to explore the resonance performance of the floor. The predictability of marked resonance issues is thus analyzed, with respect to the reference performanceindicators.
\end{abstract}

Keywords: Vibrations; non-isolated CNC machines; inter-story floor; dynamic experiments; MEMS accelerometers; synthetized signal; FE numerical modelling

\section{Introduction}

\subsection{Motivation}

For civil engineering applications, the early prediction (and control, or mitigation) of unfavourable vibration phenomena is implicitly related to the serviceability checks that should be conventionally carried out at the preliminary stage of the structural design process. In doing so, the load-bearing structure to verify must be properly characterized in the dynamic parameters. How ever, the expected source of vibration needs further detailing. In the case of inter-story floors, their vibration response mainly depends on a combination of masses, stiffness properties and damping of structural members, equipment and services, etc. As such, knowledge is required for their (i) geometry, (ii) boundary conditions, (iii) characteristics of the materials in use (and in particular the MoE), as well as for the calibration of (iv) any source of damping, and (v) the distribution and magnitude of permanent loads (self-w eight and superimposed dead loads), plus the accidental loads. When these floors are expected to carry heavy equipment, the machine-structure interaction should focus also on (vi) the magnitude and distribution of superimposed masses, but also (vii) the features of the vibration sources (magnitude, frequency content, etc.), given that they are both responsible of severe modifications in the dynamic equilibrium and parameters of empty floors [9-12]. Major effects due to unfavourable resonance effects could in fact significantly affect the workers' comfort, but also the integrity of the structural members. Moreover, machine-induced vibrations could transmit for long distances, thus to a huge number of load-bearing components. 
This paper investigates the potential of an improved coupled experimental-numerical approach for predictive vibration serviceability studies of industrial buildings with heavy CNC machines. To this aim, a case-study industrial building in Italy, hosting an eyewear factory, is taken into account. The extended discussion of test methods and analysis procedures is further reported in [13]. More in detail, a coupled experimental-numerical approach is presented and validated in this paper, $w$ ith the support of a refined modeling detailing for the structure [14], but also of dedicated experimental acquisitions with MEMS accelerometers [15]. Generally speaking, the use of sensors for machinery diagnostics and early prevention is established since years [16], see Figure 1.

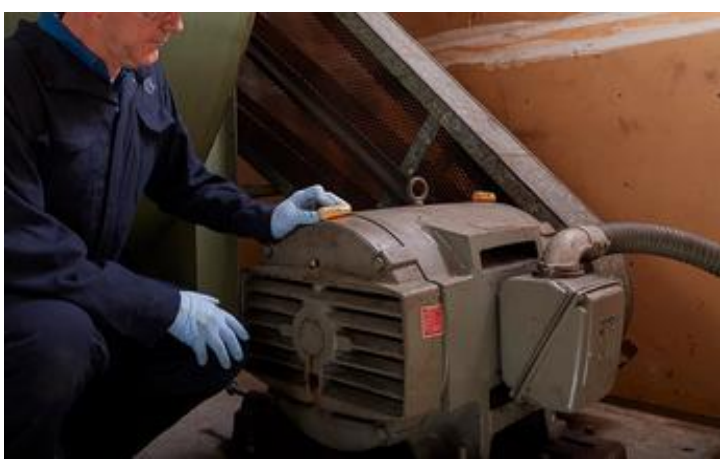

(a)

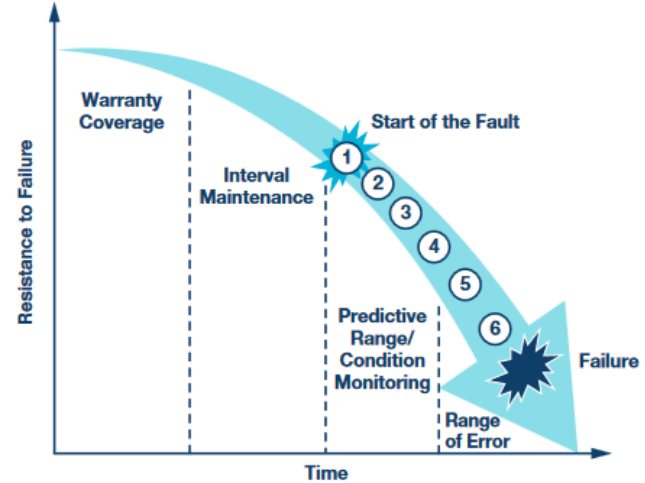

(b)

Figure 1. Vibration monitoring for machines: (a) typical setup and (b) schematic representation of machine life cycle assessment (a dapted from [16]).

Various research studies have been also dedicated to the vibrational characterization of specific machinery tools. Differing from past literature studies that have been focused on machine-induced vibrations on rigid foundation systems (i.e., [9-12]), or on the machinery characterization only [1719], how ever, the attention of the experimental and FE numerical analysis reported in this paper is in fact dedicated to the movable components of the machines and on the corresponding response of the primary structure. The final result takes the form of a synthetized signal for the CNC machine that can be used for refined numerical analyses of the primary system. Moreover, on the side of the structure, the refined calibration of other relevant FE input parameters (such as material properties and damping) can be further exploited from the available experimental data, with remarkable improvement of the FE dynamic predictions.

\subsection{Reference stantards}

Besides the availability of several tools, the topic is not well addressed by the available design standards for structures, and thus even underrated by structural designers. For example, the general recommendation of the existing Eurocodes is to supply lower limits for the natural fundamental frequency of floors, depending on their prevailing constructional material [20]. Such a requirement, however, is still limited to human comfort assessment, and does not apply to floors with working machines. The NTC2018 standard [21,22], in this regard, recommends that -in case of floors with a fundamental vibration frequency low er or equal than $5 \mathrm{~Hz}$ - "specific calculation methods" should be adopted to avoid vibration issues for the comfort of occupants.

In the case of industrial floors with machines, major issues for structural designers can derive from the lack of any kind of detailing about the machine-structure interaction assessment. Sometimes, the structural designer is aw are of the final destination of the building (i.e., equipment features and final layout). Moreover, it is possible that the machinery manufacturers do not provide detailed input data about the machinery activities, and thus the consequent quantification of the vibration source. Finally, it is recognized that simplified calculation methods are not able to capture the real dynamic phenomena of machine-induced vibrations. The UNI9916 standard [23], in this regard, focuses on the susceptibility of structures to experience any damage due to vibrations, based on the limitation of the velocity peak that is expected under operational conditions. For industrial 
floors with a fundamental natural frequency not higher than $10 \mathrm{~Hz}$, the velocity peak is limited to a maximum of $20 \mathrm{~mm} / \mathrm{s}$ for short-term vibrations (Figure 2).

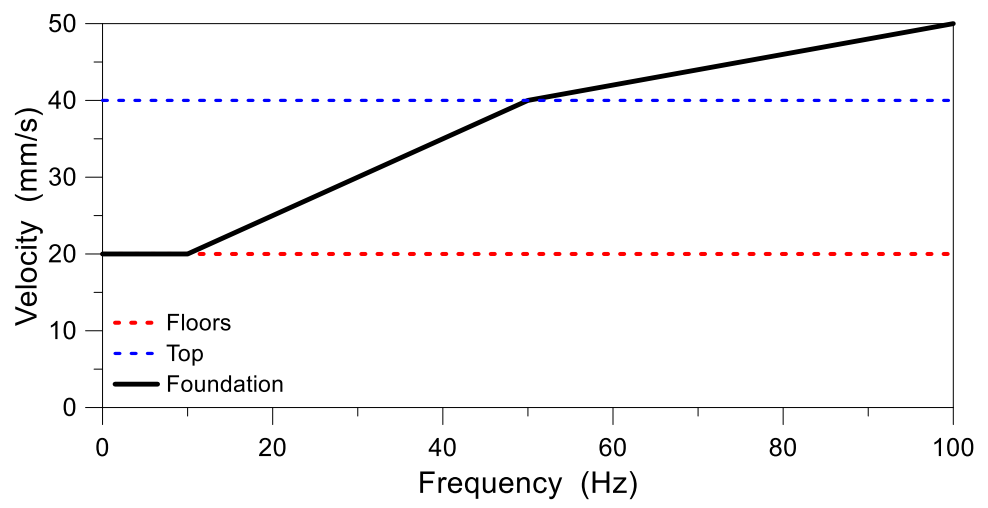

Figure 2. Reference velocity peak limits to prevent structural damage in industrial buildings exposed to short-term vibrations.

\section{Experimental and numerical study}

\subsection{Case-study building}

The production of optical glasses is based on various non-isolated CNC vertical machinery centers, as shown in Figure 3, that were mounted on the inter-story floor, with consequent severe resonance issues and management troubles for the factory.

The two-story, two-span, precast concretebuilding is in fact characterized by $13 \mathrm{~m}$ of elevation, with plan dimensions $\mathrm{Lx}_{x}=67.1 \times \mathrm{L}_{y}=30.8 \mathrm{~m}$. The grid of beams and columns defines $6 \times 2$ adjacent bays $\left(1_{x}=11 \times l_{y}=14.9 \mathrm{~m}\right.$, for each one of them). The inter-story floor object of study is supported by plinth-restrained, square columns $(80 \times 80 \mathrm{~cm}$ their cross-section $)$ and primary precast beams (spanning in the $x$ direction) at $8 \mathrm{~m}$ from the foundation. These beams cover a total span of $10.25 \mathrm{~m}$, with $0.2 \mathrm{~m}$ the width of cantilever supports that are offered by the columns.

The inter-story floor consists of a series of adjacent, unconnected double tee modular units and a continuous, cast-in-situ concrete slab on their top, that ensures the structural continuity and a certain flexural / torsional rigidity for the diaphragm. The double tee elements have cross-section features that agree with Figure 3(b). The nominal height is $h=0.8 \mathrm{~m}$, while the width $\mathrm{B}$ is equal to $2.34 \mathrm{~m}, 2.50 \mathrm{~m}$ or $2.55 \mathrm{~m}$. The distance of the webs $(\mathrm{b}=1.3 \mathrm{~m})$ and the thickness of the top cap $(\mathrm{h}$ cap $=$ $0.05 \mathrm{~m}$ ) are indeed kept fix. The double tee elements are characterized by high slenderness, given that they are simply supported over $L=14.62 \mathrm{~m}$ of span.

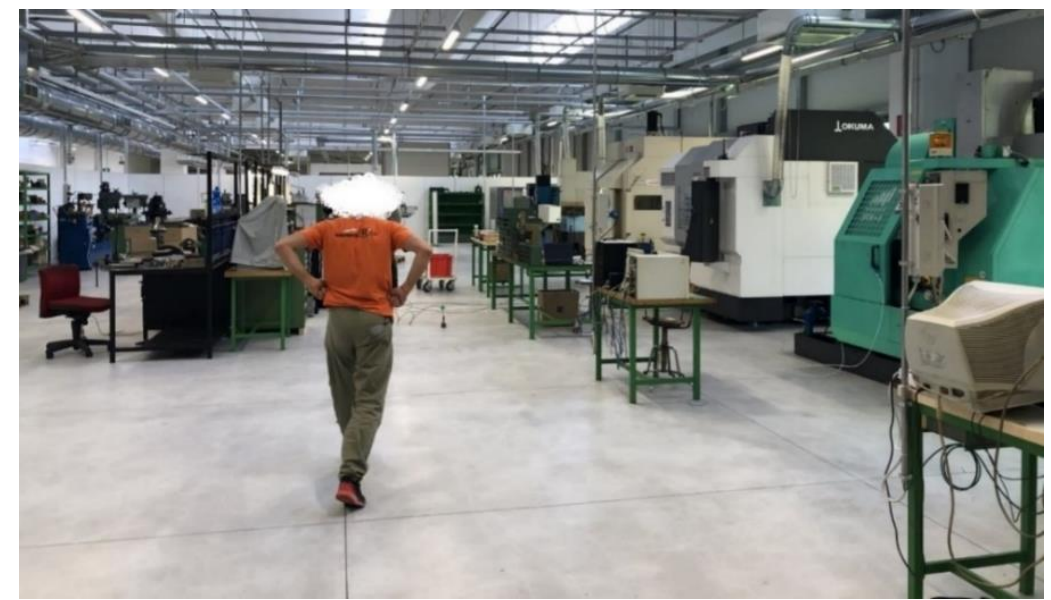

(a) 


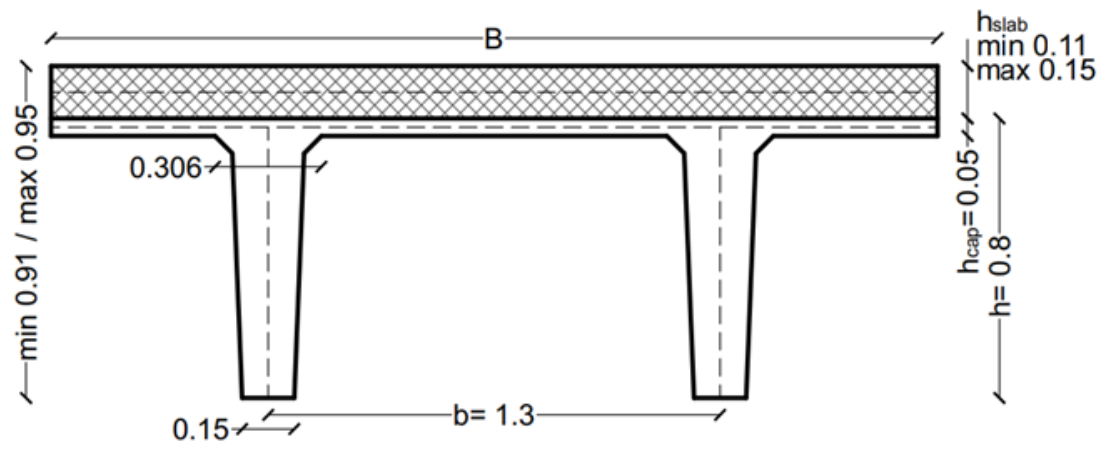

(b)

Figure 3. Reference modular unit for the inter-story floor under investigation: (a) general view, with evidence of CNC ma chine s and equipment, and (b) transversal cross-section (dimensions in $\mathrm{m}$ ).

\subsection{CNC machines}

The selected floor region object of study is composed of five modular units (Figure 4) and hosts three non-isolated machines. The schematic plan view of Figure 4 show s their footprint and layout.

The equipment, more in detail, includes an OKUMA - GENOS M560-V-e vertical machinery tool [24] with total mass MокUмA $=7700 \mathrm{~kg}$ (and $M_{\text {spindle }}=400 \mathrm{~kg}$ for the movable components) that roughly corresponds to $\approx 1 / 3$ the mass of the supporting module. Additional superimposed permanent loads are represented by MATSUURA [25] and BRIDGEPORT [26] machines (4500 kg and $2700 \mathrm{~kg}$ respectively) and the corresponding equipment ( $\approx 150 \mathrm{~kg} /$ machine).

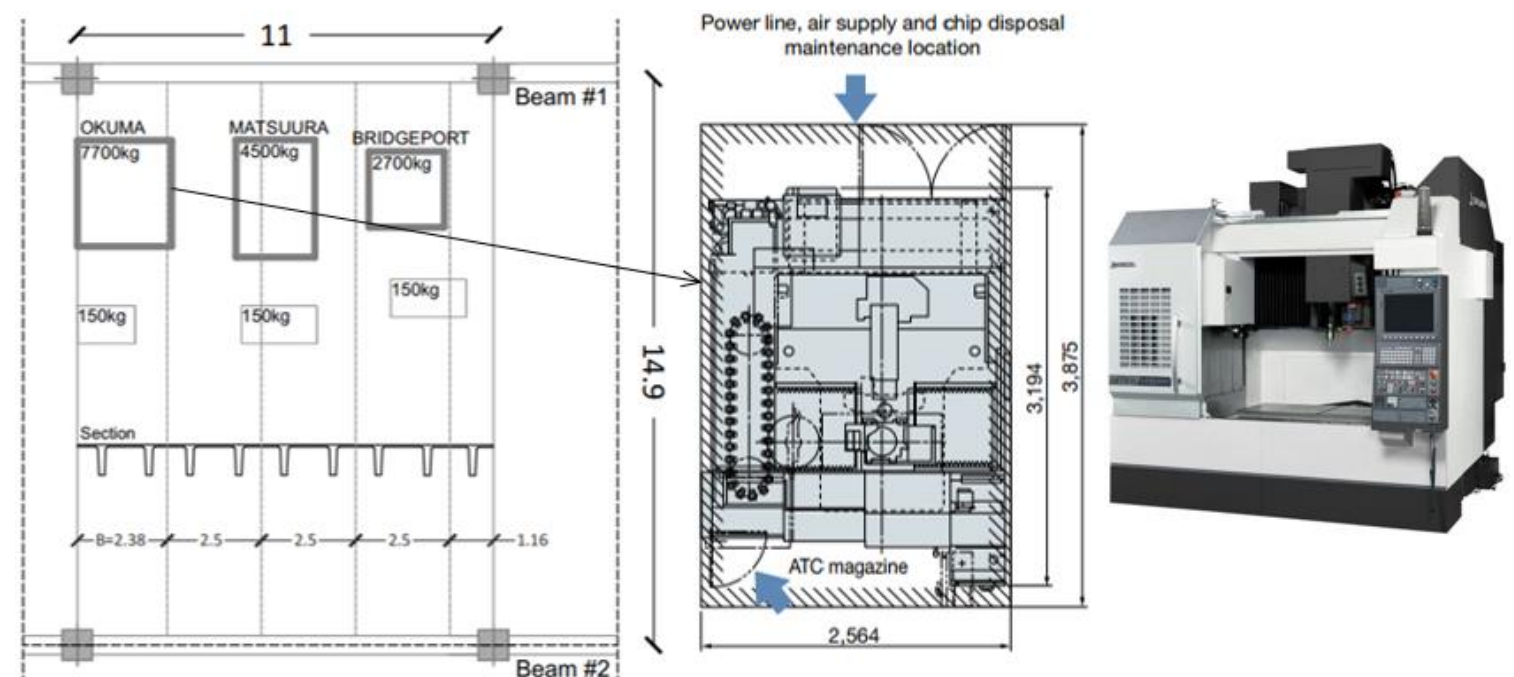

Figure 4. Plan view of the floor region of study (dimensions in $\mathrm{m}$ ), with de tails of the CNC machines.

\subsection{Experimental methods}

A series of on-site dynamic experiments w as carried out on the inter-story floor region in Figure 4, to explore its dynamic performance under the w orking CNC machines. In total, 12 machinery/floor measurements were acquired from different configurations (by varying the reference mach ine, the assigned working process, the layout of instruments for the measurement of accelerations). Major outcomes are discussed in Section 3 and [13].

\subsection{Finite Element numerical model}

An extended numerical analy sis w as carried out in ABAQUS/Standard, based on a geometrically simplified but accurate FE model, that was validated to capture the vibrational response of the interstory floor [13]. The selected floor region in Figure 4 was thus described, at the local level, with appropriate boundaries and kinematic constraints. S4R shell elements were used for the double tee modules (Figure 5). In the case of the webs, $0.1 \mathrm{~m}$ high shell elements with average thickness were 
used, while the slab w as described with S4R elements and offset. A variable shell thickn ess was used along the span $(0.2 \mathrm{~m}$ long segments), to account for the slab geometry. A distributed "tie" constraint was used between the precast and cast-in-situ shell elements. The floor region was thus assembled through adjacent precast modules and a continuous slab, but also including the supporting beams and columns (Figures 5 and 6). 3D solid elements were used for them, to account for their restraint effect on the floor. Each precast web was thus locally connected to the beams with a shell-to-solid constraint. Additional boundaries were defined along the slab edges, due to continuity.

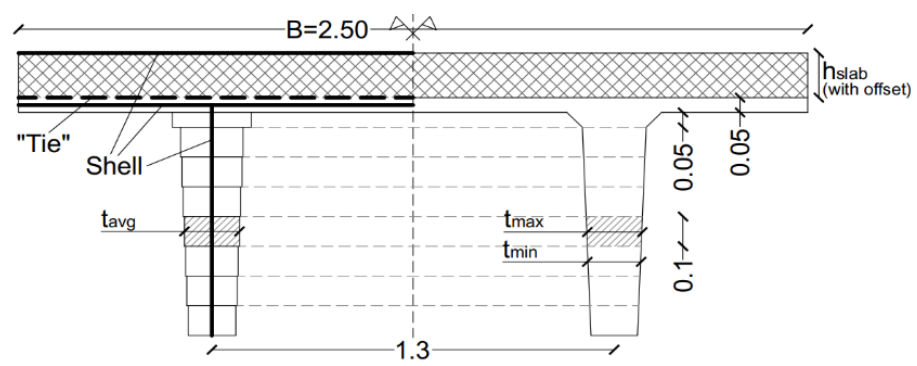

(a)

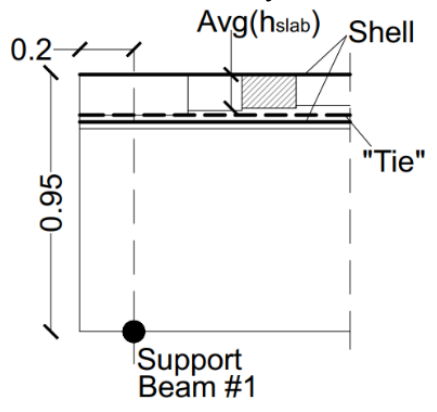

(b)

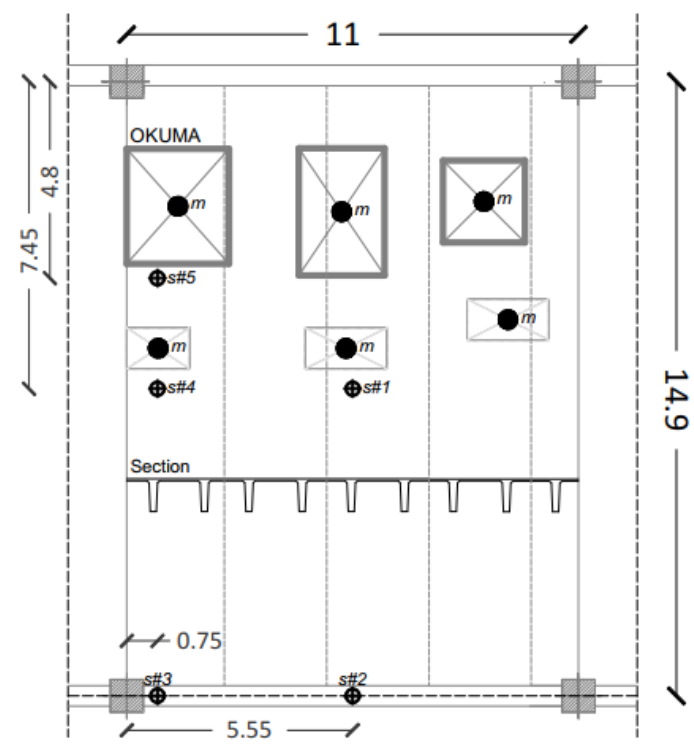

(c)

Figure 5. Modelling of the modular elements: (a) cross-section (example for $B=2.5 \mathrm{~m}$ ) and (b) side view, with (c) final layout of the assembled floor region (plan view). All dimensions in $\mathrm{m}$.

Regarding the machines schematized in Figure 5(c), a mixed approach w as taken into account. A series of distributed masses was first used to reproduce the actual position of the sustained weights. In the case of the OKUMA machine, see Figure 6, an additional lumped term (Mspindle) with a rigid link was used for the spindle movements.

In this manner, the analysis was focused both on the prediction of the natural vibration modes of the floor (that can be affected by the masses of the machines at rest), as well as on the additional dynamic effects deriving from the operative OKUMA center. The input acceleration was hence derived from MEMS acquisitions on the machine. 


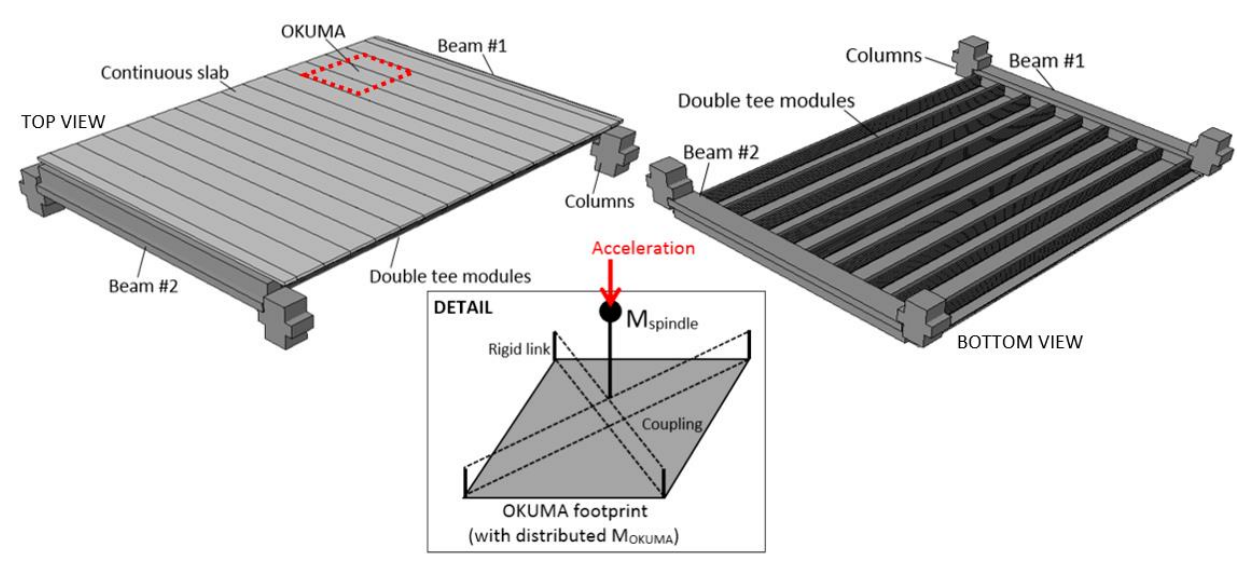

Figure 6. Layout of the FE model for the area of investigation of the inter-story floor (ABAQUS/Standard).

\section{Discussion of results}

\subsection{CNC machinery center and inter-story floor measurements}

Under the typical operational conditions for the eyewear factory object of study, the spindle in Figure 7(a) was found subjected to cyclic vertical displacements and accelerations that are directly transferred to the supporting floor (non-isolated base restraints). During the field experiments, careful attention $w$ as thus paid to capture the key features of the input vibrational source. Such a goal w as achieved with the support of a digital tri-axial accelerometers (ADXL355 type) that was mounted on the moving spindle. Among the various working programs of the OKUMA machine, the worst operational condition was taken into account for the analysis of the inter-story floor, and thus for the validation of the coupled experimental-numerical procedure. The corresponding acceleration-time history is shown in Figure 7(b).

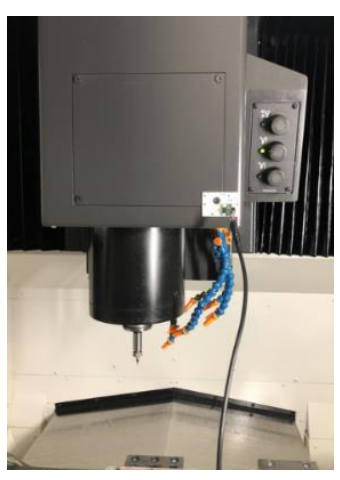

(a)

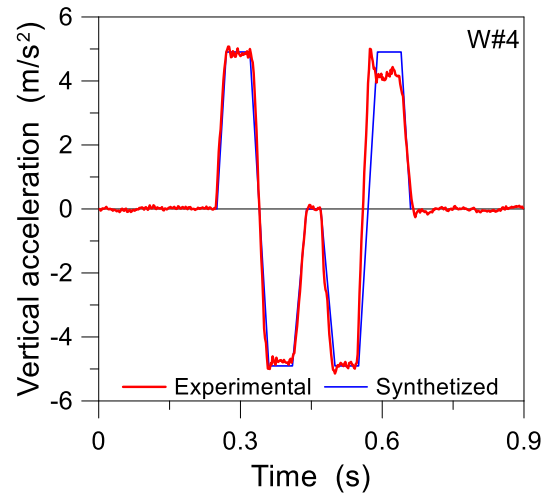

(b)

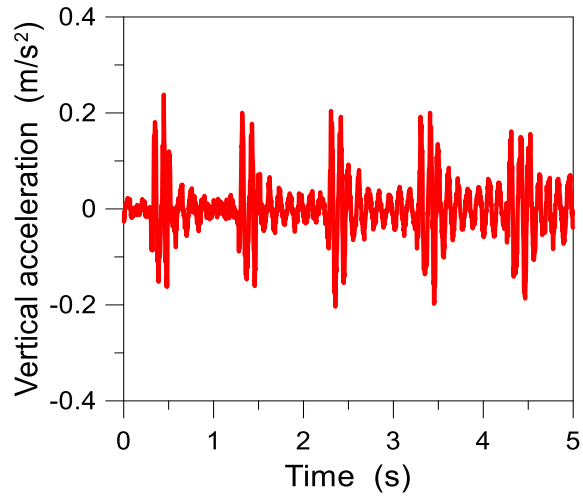

(c)

Figure 7. Experimental outcomes: (a) de tail of the OKUMA moving spindle, with (b) de rivation of the synthetized signal (single cycle) and (c) corresponding vertical acceleration of the floor (s\#4) under the worst operational condition.

In parallel, additional experimental records w ere collected for the inter-story floor, with a digital tri-axial accelerometer (ADXL355 type) that was variably positioned on the floor region object of study (s\#n labels in Figure 5(c)), under the effects of the working OKUMA. An example is proposed in Figure 7(c), with evidence of the first five seconds of measurements, as obtained from the sensor $\mathrm{s} \# 4$. The vertical acceleration peak w as measured in $0.26 \mathrm{~m} / \mathrm{s}^{2}$. From the post-processing stage of test measurements, moreover, the first tw ofundamental vibration frequencies of the floor w ere detected in the order of $\mathrm{f}_{1, \exp }=7.4 \mathrm{~Hz}$ and $\mathrm{f}_{2, \exp }=9.4 \mathrm{~Hz}$. 
A linear "frequency" analysis was first carried out on the floor with the sustained masses only of the CNC machines at rest. The low er fundamental modes are proposed in Figure 8 and are ty pically associated, as also expected, to global platebending deformation of the whole inter-story floor. This is also confirmed by the validation of the one-bay FE model towards a more extended and geometrically complex FE model of the same structure[13].

Worth of interest from Figure 8 is the good correlation of the numerically predicted frequencies with the experimental derived frequencies of the floor ( $w i t h f_{1, \exp }=7.4 \mathrm{~Hz}$ and $\mathrm{f}_{2, \exp }=9.4 \mathrm{~Hz}$ respectively). Moreover, from the FE analy sis of the structure with the CNC machines at rest, the total machinery mass was found responsible of a $-6 \%$ variation for the calculated low er frequencies (with $\mathrm{f}_{1, \text { empty }}=7.81 \mathrm{~Hz}$ and $\left.\mathrm{f}_{2, \text { empty }}=9.98 \mathrm{~Hz}\right)$.

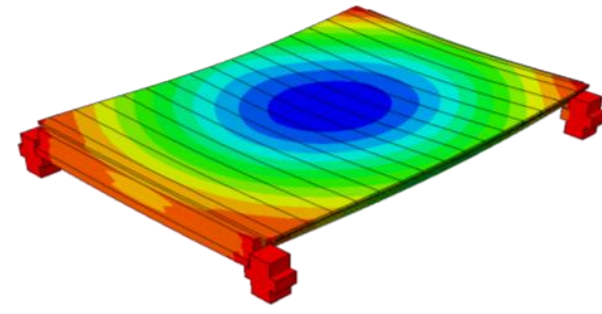

$$
f_{1}=7.37 \mathrm{~Hz}
$$

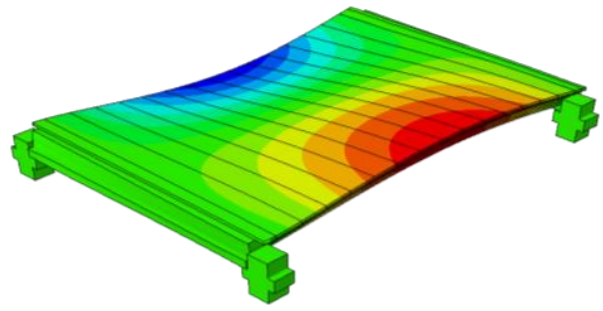

$f_{2}=9.41 \mathrm{~Hz}$

Figure 8. Numerical derivation of the fundamental vibration modes of the floor with $\mathrm{CNC}$ machines at rest (ABAQUS/Standard).

The conventional Steady State Dynamics (SSD) analysis was successively carried out on the FE model of Figure 6 , under the W\#4 cyclic input vibrations. In doing so, a total damping $\xi_{\exp }=9 \% \mathrm{w}$ as taken into account for the analyses, based on the experimental feedback [13].

Major FE outcomes and selected SSD results are proposed in Figure 9. More in detail, the estimated SSD acceleration an velocity of the floor are shown in Figure 9(a) as a function of the frequency of the system, with a focus on the s\#1 and $\$ 44$ numerical estimates, compared to the s\#4 experimental peak. The confirmation that the structure suffers for marked resonance issues in the W\#4 setup can be noticed in Figure 9(a) for the range of the examined natural frequencies of the floor. Moreover, the $\# 4$ control point and the second mode of vibration of the structure were usually found to be associated with more pronounced dynamic effects, compared to the central s\#1 point, as a result of the machine-induced vibrations and the related torsional deformations of the deck.

Figure 9(b) shows the experimental and FE numerical acceleration peaks from the same SSD analysis, as far as the $\mathrm{s} \# 4, \mathrm{~s} \# 5$, and $\mathrm{mp} \# 2$ control point are taken into account. It is possible to see a rather close correlation of measurements on the side of the floor, while the rigid link-based mechanical system in Figure 5 tends to underestimate the corresponding experimental measurement, due to the lack of detailing on the side of machinery components. In this regard, it is important to remind that the goal is to assess the effects of input machinery vibrations on the primary structureand that the coupled procedure properly captures - rather than the local characterization of the machinery components. Further operational conditions and influencing parameters are hence discussed in [13]. 


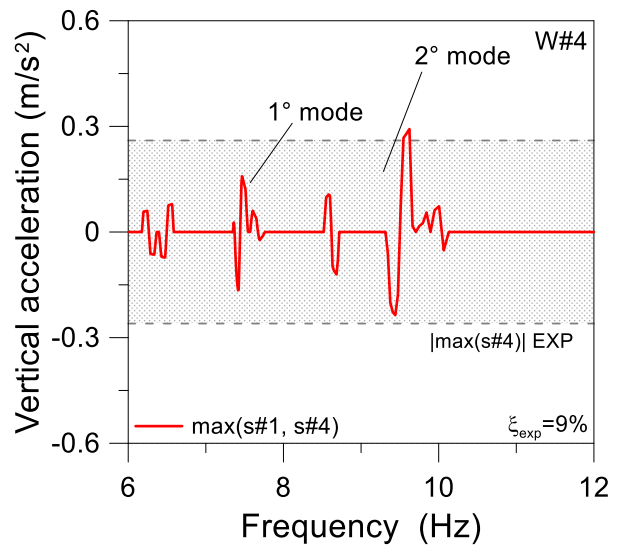

(a)

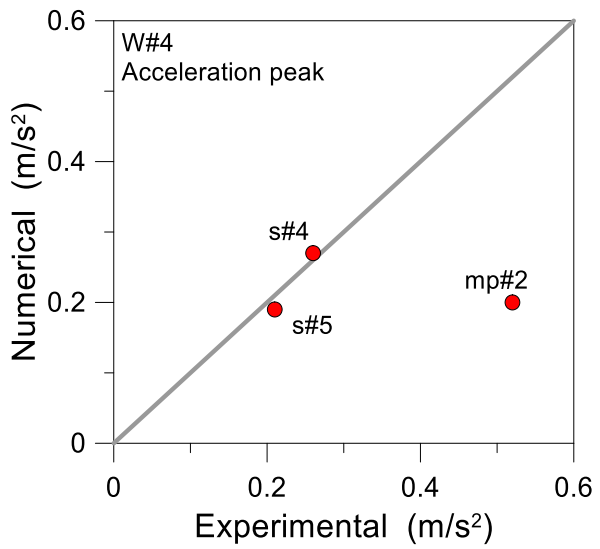

(b)

Figure 9. SSD analysis of the inter-story floor region with the working OKUMA (ABAQUS/Standard, one-bay FE model, W\#4). Evolution of (a) vertical a cceleration peaks in the s\#1 and s\#4 control points, with (b) comparison of absolute acceleration peaks for the $\mathrm{W} \# 4$ experimental configuration (SSD analyses based on the OKUMA synthe tized signal).

\subsection{Vibration serviceability assessment}

The refined structural FE model of the floor was used for additional comparative studies and vibration serviceability analyses [13]. In this regard, Figure 10 shows the acceleration, velocity and displacement peaks for the $W \# 4$ program, as a function of the FE input parameters for concrete $(\mathrm{MoE})$ and damping. As known, the availability of reliable FE estimates represents a strategic feedback in support of the early design stage of buildings (and thus a crucial input for the original design of the case-study factory), and thus an important outcome that suggests the predictivity of possible vibration issues. Figure 10 gives evidence (for the W\#4 process) of "experimental" and "design" modeling assumptions for the investigated floor. Worth of interest the remarkable scatter of the collected numerical predictions, as a function of the input parameters. The "design" W\#4 velocity estimates, more in detail, were found to roughly approach the reference velocity limit of $20 \mathrm{~mm} / \mathrm{s}$ for structural damage prevention, thus representing a potential early warning for the overall design process. From the vertical displacements of the floor, see Figure 10(c), the corresponding DAF was calculated up to +6.2 for the $\mathrm{W} \# 4$ program, thus representing another early warning parameter to account in preliminary design decisions.

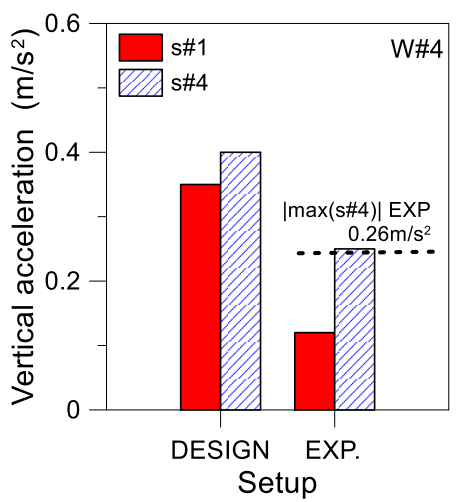

(a)

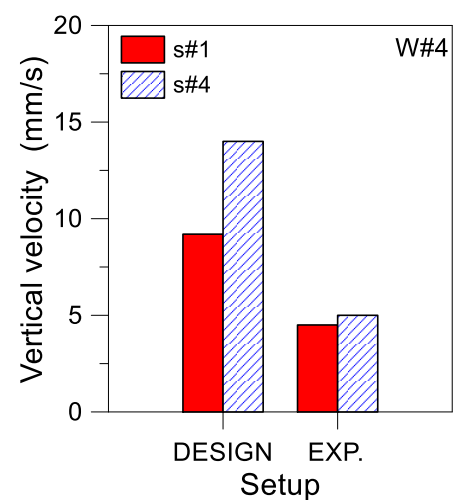

(b)

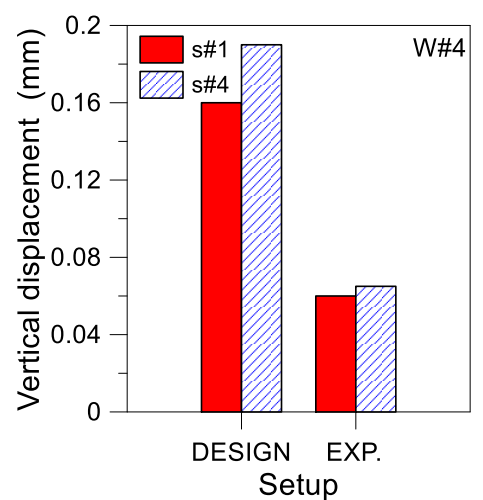

(c)

Figure 10.SSD analysis of the inter-story floor region with the working OKUMA (ABAQUS/Standard, one-bay FE model, W\#4): (a) vertical acceleration, (b) velocity, and (c) dis placement peaks in the s\#1 and $\mathrm{s} \# 4$ control points, as a function of the dynamic MoE of concrete (nominal vs. experimental) and damping (nominalvs. experimental).

\section{Conclusions}


The prediction of machine-induced vibrations is a key step for the early design stage. How ever, the description of the vibration source, as well as the reliability of the available structural models, can be challenging. In this paper, a case-study eyewear factory was investigated, with a focus on the vibration issues of its floor, where non-isolated CNC machines were mounted. An experimental characterization of the machinery activity was presented. The reliable FE analysis of the floor was thus carried out with realistic input excitations. The good match of field and numerical predictions confirmed the added value of coupled experimental-numerical predictive studies, so as to prevent (or mitigate) possible machine-induced vibrational issues.

Acknowledgments: The IECAT2020 (1st International Electronic Conference on Actuator Technology: Materials, Device s and Applications) Organizing Team, the Conference Chairs and Committee a re acknowledged for the intere st and positive evalua tion of the submitted re search topic.

Author Contributions: This research paper results from a joint collaboration of all the involved authors. All the authors have read and agreed to the published version of the manuscript. E.B. and M.F. handled the field experimental analysis and post-processing stage, while C.B. took care of the numerical analysis. All the authors contributed to the discussion and analysis of compa rative results, and thus to the drafting of the final document.

Conflicts of Interest: The authors declare no conflict of interest.

\section{Abbreviations}

The following abbreviations are used in this manuscript:

CNC: computer numerical control

DAF: dynamic amplification factor

FE: finite element

MEMS: micro electro-mechanical systems

MoE: modulus of elasticity

\section{References}

1. Bachmann, H.; Ammann, W. Vibrations in Structures Induced by Man and Machines; IABSE-International Association for Bridge and Structural Enginee ring: Zurich, Switze rland, 1987; ISBN 3-85748-052-X.

2. Feldmann, M.; Heinemeyer, C.; Butz, C.; Caetano, E.; Cunha, A.; Galanti, F.; Goldack, A.; Hechler, O.; Hicks, S.; Keil, A.; et al. Design of Floor Structures for Human Induced Vibrations; Technical Report EUR 24084 EN.; Publications Office of the Europe an Union: Bruxelles, Belgium, 2009; doi:10.2788/4640; ISBN 978-9279-14094-5.

3. Da Silva, J.G.S.; Sieira, A.C.C.F.; Da Silva, L.A.P.S.; Rimola, B.D. Dynamic Analysis of Steel Platforms When Subjected to Mechanical Equipment-Induced Vibrations. J. Civ. Eng. Arch. 2016, 10, 1103-1113, doi:10.17265/1934-7359/2016.10.003.

4. Brownjohn, J.; Pavic, A. Vibra tion control of ultra-sensitive facilities. Proc. Inst. Civ. Eng. Struct. Build. 2006, 159, 295-306, doi:10.1680/stbu.2006.159.5.295.

5. Chang, M.-L.; Lin, C.-C.; Ueng, J.-M.; Hsieh, K.-H.; Wang, J.-F. Experimental study on adjustable tuned mass damper to reduce floor vibration due to machinery. Struct. Control Health Monit. 2009, 17, 352-548, doi:10.1002/stc.330.

6. Kazantzi, A.K.; Vamvatsikos, D. Seismic and Vibration Performance Rehabilita tion for an IndustrialSteel Building. Pr. Period. Struct. Des. Constr. 2020, 25, 05020001, doi:10.1061/(asce)sc.1943-5576.0000475.

7. Wilson, R.R. Machine Founda tions. In Vibrations of Engineering Structures; Lecture Notes in Enginee ring; Springer: Berlin/Heidelberg, Germany, 1985; Volume 10; doi:10.1007/978-3-642-82390-9_10.

8. Tian, Y.; Liu, Z.; Xu, X.; Wang, G.; Li, Q.; Zhou, Y.; Cheng, J. Systematic review of re search relating to heavyduty machine tool foundation systems. Adv. Mech. Eng. 2019, 11, doi:10.1177/1687814018806106.

9. Stimac, G.; Braut, S.; Zigulic, R. Structural optimization of turbine gene rator foundation with fre quency constraint. Strojarstvo 2011, 53, 389-398.

10. Liu, J.B.; Wang, Z.Y.; Zhang, K.F.; Pei, Y.X.3D Finite elementanalysis of large dynamic machine founda tion considering soil-structure interaction. Eng. Mech. 2002, 19, 34-35.

11. Tian, Y.; Shu, Q.; Liu, Z.; Ji, Y. Vibration Characteristics of Heavy-Duty CNC Machine Tool-Foundation Systems. Shock. Vib. 2018, 2018, 1-12, doi:10.1155/2018/4693934. 
12. Werner, U. Derivation of a plane vibration model for electrical machines on soft machine foundations. Forsch. im Ing. 2010, 74, 185-205, doi:10.1007/s10010-010-0125-0.

13. Bergamo, E.; Fasan, M.; Bedon, C. Efficiency of Coupled Experimental-Numerical Pre dictive Analyses for Inter-Story Floors Under Non-Isolated Machine-Induced Vibrations. Actuators 2020, 9, 87, doi: $10.3390 /$ act 9030087

14. ABAQUS computer software. Simulia: Providence, RI, USA, 2020.

15. Bedon, C.; Bergamo, E.; Izzi, M.; Noé, S. Prototyping and Valida tion of MEMS Accele rometers forStructural Health Monitoring-The Case Study of the Pietrataglia ta Cable-Stayed Bridge. J.Sens. Actuator Netw. 2018, 7, 30, doi:10.3390/jsan7030030.

16. Brand, T. Demands on Sensors for Future Servicing: Smart Sensors for Condition Monitoring, 2017. Available online: https://www.analog.com/media/en/technical-documentation/tech-articles/A60151Demands-on-Sensors-for-Future-Servicing-Smart-Sensors-for-Condition-Monitoring.pdf (last accessed on November 7, 2020)

17. Cizikova, A.; Monkova, K.; Monka, P.; Moravec, M. Analysis of frequency characteristics at spindle of CNC machining centre. MMSci. J. 2016, 2016, 1515-1518, doi:10.17973/MMSJ.2016_12_201627.

18. Abdulhani, F.; Alswe de, J. Study of vibration for CNC machine at diffe rent feed. Int. J. Adv. Res. Technol. 2014, 3, 21-29.

19. Dogrusoz, H.; W szolek, G.; Czop, P.; Slonie wski, J. Vibration monitoring of CNC machinery using MEMS sensors. J. Vibroengineering 2020, 22, 735-750, doi:10.21595/jve.2019.20788.

20. Eurocodice 4 - Progettazione Delle Strutture Composte Acciaio-Calcestruzzo-Parte 1-1: Regole Generalie Regole per Gli Edifici; UNI EN 1994-1-1:2004; Ente Nazionale Italiano diUnificazione (UNI): Milan, Italy, 2005.

21. Ministero delle Infrastrutture e dei Trasporti-DM 17/01/2018. Norme Tecniche per le Costruzioni (NTC2018), 2018.

22. Ministe ro delle Infrastrutture e dei Tras porti-Circola re n.7 de121/01/2019-Istruzioni per l'a pplicazione dell' "Aggiornamento delle Norme Tecniche per le Costruzioni", 2019.

23. Criteridi Misura e Valutazione Degli EffettiDelle VibrazioniSugli Edifici; UNI9916: 2014; Ente Nazionale Ita liano di Unificazione (UNI): Milan, Italy, 2014.

24. OKUMA Europe GmbH. Available online: www.okuma.eu (accessed on July 27, 2020).

25. MATSUURA Machinery Corporation. Available online: https://www.matsuura.co.jp/english/ (accessed on July 27, 2020).

26. BRIDGEPORT Machines. Available online: https://www.hardinge.com/product-brand/bridgeport/ (accessed on July 27, 2020).

(C) 2020 by the authors; licensee MDPI, Basel, Switzerland. This article is an open access article distributed under the terms and conditions of the Creative Commons by Attribution (CC-BY) license (http://creativecommons.org/licenses/by/4.0/). 